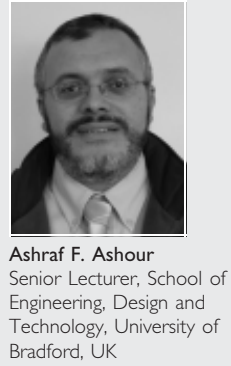

\title{
Inclined reinforcement around web opening in concrete beams
}

\author{
K.-H. Yang MSc, PhD, Archi. Engng and A. F. Ashour MSc, PhD, CEng, MIStructE
}

Twelve reinforced-concrete continuous deep beams having web openings within interior shear spans were tested to failure. The main variables investigated were the opening size and the amount of inclined reinforcement around openings. An effective inclined reinforcement factor combining the influence of the amount of inclined web reinforcement and opening size is proposed and used to analyse the structural behaviour of continuous deep beams tested. It was observed that the end support reaction, diagonal crack width and load capacity of beams tested were significantly dependent on the proposed effective inclined reinforcement factor. As this factor increased, the end support reaction and increasing rate of diagonal crack width were closer to those of companion solid deep beams. In addition, a higher load capacity was exhibited by beams having an effective inclined reinforcement factor above 0.077 than the companion solid deep beam. A numerical procedure based on the upper-bound analysis of the plasticity theory was proposed to estimate the load capacity of beams tested. Comparisons between the measured and predicted load capacities showed good agreement.

\section{NOTATION}

$A_{d 1} \quad$ area of inclined reinforcement

$A_{\mathrm{s}} \quad$ area of longitudinal bottom reinforcement

$A_{s}^{\prime} \quad$ area of longitudinal top reinforcement

$A_{\text {st }}$ area of the reinforcing bar crossing a yield line

a shear span

$b_{\mathrm{w}} \quad$ width of beam section

$d \quad$ effective depth of beam section

$d_{\mathrm{a}} \quad$ maximum size of aggregate

$d_{\mathrm{s}} \quad$ depth of concrete strut

$E_{\mathrm{s}} \quad$ elastic modulus of reinforcement

$\boldsymbol{f}_{\mathrm{c}}^{\prime} \quad$ cylinder compressive strength of concrete

$\boldsymbol{f}_{\mathrm{c}}^{*} \quad$ effective strength of concrete

$\boldsymbol{f}_{\mathrm{su}} \quad$ tensile strength of reinforcement

$f_{\mathrm{y}} \quad$ yield strength of reinforcement

$h$ overall depth of beam section

$k_{2} \quad$ ratio of distance between soffit of the beam and bottom face of opening to section depth

$l \quad$ length of yield line

$m_{1} \quad$ ratio of opening width to shear span

$m_{2} \quad$ ratio of opening depth to overall section depth

$n \quad$ number of inclined reinforcement

$\boldsymbol{P}_{n} \quad$ total load capacity $r \quad$ distance between the midpoint of the chord of the yield line and the instantaneous centre (IC)

$r_{\mathrm{s}} \quad$ distance between the intersection point of reinforcing bar with yield line and the IC

$\alpha \quad$ angle between the relative displacement and yield line

$\alpha_{\mathrm{s}} \quad$ angle between the relative displacement about IC and the reinforcing bar crossing yield line

$\beta \quad$ angle between the inclined reinforcement and the longitudinal axis of member

$\Delta \quad$ notional width of a yield line

$\boldsymbol{\delta}$ relative displacement vector across a yield line

$\boldsymbol{\varepsilon}_{1,3} \quad$ principal strain in a yield line

$\boldsymbol{\varepsilon}_{\mathrm{y}} \quad$ yield strain of reinforcement

$\varsigma \quad$ size effect factor

$\theta \quad$ angle of a failure plane to the longitudinal axis of member

$v_{\mathrm{e}} \quad$ effectiveness factor of concrete

$\xi \quad$ effective inclined reinforcement factor defined by equation (1)

$\rho_{0 \mathrm{~A}} \quad$ ratio of opening area to shear span area

$\rho_{\mathrm{s}} \quad$ longitudinal bottom reinforcement ratio

$\rho_{\mathrm{s}}^{\prime} \quad$ longitudinal top reinforcement ratio

$\phi_{\mathrm{s}} \quad$ reinforcement index $\left(=\frac{A_{\mathrm{st}} f_{\mathrm{y}}}{b_{w} h f_{\mathrm{c}}^{\prime}}\right)$

\section{INTRODUCTION}

Reinforced-concrete deep beams such as transfer girders, pile caps and foundation walls in tall buildings commonly have several supports. The coexistence of high shear and high moment within interior shear spans in continuous deep beams has a considerable effect on the development of cracks, leading to a significant reduction in the effective strength of the concrete strut joining the load and support points, which is the main load transfer element in deep beams. A few test results ${ }^{1-3}$ also showed that shear capacity within interior shear spans in continuous deep beams generally decreased compared with that of simply supported deep beams.

Openings are frequently placed in the web area of reinforcedconcrete deep beams in order to facilitate essential services, such as conduits, water supply and drainage pipes, network system access or even movement from one room to another. These openings often interrupt the load transfer by concrete struts and can cause a sharp decrease of strength and serviceability of deep beams. ${ }^{4-6}$ Many diagonal cracks can also be developed above and below openings in reinforced-concrete deep beams owing to high stress concentration at corners and 
the abrupt change of the main load path. In addition, the experimental investigation carried out by Ashour and Rishi ${ }^{7}$ showed that the structural behaviour of continuous deep beams such as failure mode, load transfer mechanism and load capacity was significantly dependent on size and location of web openings and different from that of simply supported deep beams.

Proper arrangement of web reinforcement around openings enables diagonal cracks to be controlled above and below openings and enhances the load capacity of deep beams. From the few test results ${ }^{5,8,9}$ of simple deep beams, it was concluded that inclined reinforcement around openings is more effective in improving the ultimate shear strength of deep beams with openings than horizontal or vertical reinforcement. Very few, if any, available data on the effect of inclined reinforcement around openings on the structural behaviour of continuous deep beams were, however, published. Furthermore, their design guidelines have not been provided yet by most code provisions. ${ }^{10-13}$ A reasonable evaluation of the influence of web openings and inclined reinforcement on structural behaviour of continuous deep beams therefore requires further investigation.

The objective of the present study is to evaluate the effect of the opening size and amount of inclined reinforcement around openings on controlling diagonal cracks and load capacity of continuous deep beams. Twelve reinforced-concrete continuous deep beams with web openings were tested to failure. Four sizes of web openings and three values of inclined reinforcement were investigated. The structural behaviour of beams tested is analysed against the effective inclined reinforcement factor proposed by Yang et al. ${ }^{9}$ and compared with that of a companion solid deep beam ${ }^{14}$ having the same geometrical dimension and longitudinal top and bottom reinforcements. The measured load capacity is also compared with the prediction obtained from a numerical technique based on upper-bound analysis of the plasticity theory.

\section{RESEARCH SIGNIFICANCE}

Web openings within interior shear spans of continuous deep beams cause a significant reduction of load capacity and reinforcement details around web openings are an essential consideration for safe design of such members. Available data on tests of continuous deep beams with web reinforcement around web openings are, however, scarce. The present study shows that the structural behaviour of continuous deep beams having openings within interior shear spans is significantly influenced by an effective inclined reinforcement factor. The load capacity of deep beams having openings within interior shear spans is reasonably predicted using a numerical technique based on upper-bound analysis of the plasticity theory.

\section{EFFECTIVE INCLINED REINFORCEMENT FACTOR}

Propagation of diagonal cracks above and below web openings and load capacity of deep beams with openings would be greatly influenced by reinforcement around openings and the ratio of opening area to shear span area. Yang et al. ${ }^{9}$ suggested an effective inclined reinforcement factor $\xi$ to account for the influence of opening size and amount of reinforcement around openings on the structural behaviour of deep beams as follows

\begin{tabular}{|l|l|}
\hline $\mathrm{I}$ & $\xi=\frac{n_{\mathrm{t}} A_{d 1} \sin \left(\beta_{\mathrm{t}}+\theta_{\mathrm{t}}\right)+n_{\mathrm{b}} A_{d 1} \sin \left(\beta_{\mathrm{b}}+\theta_{\mathrm{b}}\right)}{m_{1} m_{2} b_{\mathrm{w}}\left[k_{2} h / \sin \theta_{\mathrm{b}}+\left(1-k_{2}-m_{2}\right) h / \sin \theta_{\mathrm{t}}\right]}$ \\
\hline
\end{tabular}

where subscripts $\mathrm{t}$ and $\mathrm{b}$ indicate the top and bottom chords above and below openings, respectively; $n$ and $A_{d 1}$ are the number and area of inclined reinforcement around openings, respectively; $\beta$ is the angle between inclined reinforcement and the longitudinal axis of the beam; $\theta$ is the angle of the failure plane to the longitudinal axis of the beam; $h$ is overall section depth; $m_{1}$ is the ratio of opening width to shear span; $m_{2}$ is the ratio of opening depth to overall section depth; $k_{2}$ is the ratio of distance between soffit of the beam and bottom face of opening to overall section depth as shown in Fig. 1.

\section{EXPERIMENTAL INVESTIGATION}

\section{I. Test specimens}

Details of geometrical dimensions and reinforcement of test specimens are given in Table 1 and Fig. 1. Beams tested were classified into two groups according to the opening width: $\mathrm{T}$-series and F-series for opening widths of $0.25 a$ and $0.5 a$, respectively, where $a$ is the shear span. Three opening depths were studied: $0 \cdot 1 h, 0 \cdot 2 h$ and $0.3 h$. As a result, the ratio of the opening area to shear span area $\rho_{0 \mathrm{~A}}=m_{1} \times m_{2}$ were 0.025 , $0 \cdot 075,0 \cdot 1$ and $0 \cdot 15$ as given in Table 1 . Inclined web reinforcement was arranged in layers above and below openings, each consisting of two deformed bars of $10 \mathrm{~mm}$ diameter of net area $71 \mathrm{~mm}^{2}$. The angle of all inclined reinforcement was chosen to be $45^{\circ}$ to the longitudinal axis of the beams tested and placed symmetrically at the top chord above openings and bottom chord below openings as shown in Fig. 1. The effective inclined reinforcement factor $\xi$, as estimated from equation (1), ranged between $0 \cdot 0$ and $0 \cdot 171$ as given in Table 1 . The beam notation given in Table 1 includes three parts. The first letter gives the opening width: T for $0 \cdot 25 a$ and $\mathrm{F}$ for $0.5 \mathrm{a}$. The second 


\begin{tabular}{|c|c|c|c|c|c|c|c|}
\hline \multirow[t]{3}{*}{ Specimen } & \multicolumn{5}{|c|}{ Details of opening } & \multicolumn{2}{|c|}{ Inclined reinforcement } \\
\hline & \multicolumn{2}{|c|}{ Width } & \multicolumn{2}{|c|}{ Depth } & \multirow[t]{2}{*}{$\rho_{\mathrm{OA}}$} & \multirow{2}{*}{$\begin{array}{l}\text { No. and } \\
\text { diameter* }\end{array}$} & \multirow[t]{2}{*}{$\xi$} \\
\hline & $m_{1}$ & $\begin{array}{c}m_{1} a: \\
\mathrm{mm}\end{array}$ & $m_{2}$ & $\begin{array}{l}m_{2} h: \\
\mathrm{mm}\end{array}$ & & & \\
\hline $\mathrm{TI}-0$ & 0.25 & 150 & 0.1 & 60 & 0.025 & None & 0.000 \\
\hline $\mathrm{TI}-2$ & & & & & & $2 \phi 10$ & 0.086 \\
\hline $\mathrm{TI}-4$ & & & & & & $4 \phi 10$ & 0.171 \\
\hline T3-0 & & & 0.3 & 180 & 0.075 & None & 0.000 \\
\hline T3-6 & & & & & & $6 \phi 10$ & $0 \cdot 104$ \\
\hline $\mathrm{F} 2-0$ & 0.5 & 300 & 0.2 & 120 & 0.1 & None & 0.000 \\
\hline $\mathrm{F} 2-4$ & & & & & & $4 \phi 10$ & 0.051 \\
\hline$F 2-6$ & & & & & & $6 \phi 10$ & 0.077 \\
\hline F3-0 & & & 0.3 & 180 & 0.15 & None & 0.000 \\
\hline $\mathrm{F} 3-2$ & & & & & & $2 \phi 10$ & 0.021 \\
\hline F3-4 & & & & & & $4 \phi 10$ & 0.041 \\
\hline F3-6 & & & & & & $6 \phi 10$ & 0.062 \\
\hline \multicolumn{8}{|c|}{$\begin{array}{l}\text { Note: } m_{1} \text { is ratio of opening width to shear span; } m_{2} \text { is ratio of opening depth to overall section } \\
\text { depth; } \rho_{\mathrm{OA}} \text { is ratio of opening area to shear span area; and } \xi \text { is effective inclined reinforcement } \\
\text { factor given by equation }(\mathrm{I}) \text {. } \\
* \text { The same inclined reinforcement in top and bottom chords above and below openings. } \\
\text { All tested beams had the same concrete compressive strength of } 50.5 \mathrm{MPa} \text {, shear span-to-overal } \\
\text { depth ratio of } \mathrm{I} \cdot 0 \text {, and web openings within interior shear spans. }\end{array}$} \\
\hline
\end{tabular}

number 1,2 or 3 refers to an opening depth of $0 \cdot 1 h, 0 \cdot 2 h$ or $0 \cdot 3 h$, respectively. The third part is used to identify the number of inclined reinforcements around openings. For example, T12 is a continuous deep beam having an opening size of $0.25 a \times 0 \cdot 1 h$ and two inclined reinforcements $(2 \phi 10)$ placed above and below openings.

All tested beams had the same section size of $160 \times 600 \mathrm{~mm}$, shear span-to-overall depth ratio $a / h$ of $1 \cdot 0$, and web openings within interior shear spans as shown in Fig. 1. As openings within interior shear spans have a more significant effect on the behaviour of continuous deep beams than those within exterior shear spans, ${ }^{7,14}$ openings were located within interior shear spans of the beams tested. The opening centre was also positioned in accordance with that of the interior shear span area so that the opening completely interrupts the natural load path joining the load and intermediate support plates.

Three deformed steel bars of $19 \mathrm{~mm}$ diameter having $287 \mathrm{~mm}^{2}$ net area were used for each longitudinal top and bottom reinforcement. As a result, both the longitudinal top $\rho_{\mathrm{s}}^{\prime}\left(=A_{\mathrm{s}}^{\prime} / b_{\mathrm{w}} d\right)$ and bottom $\rho_{\mathrm{s}}\left(=A_{\mathrm{s}} / b_{\mathrm{w}} d\right)$ reinforcement ratios were the same in all beams tested at 0.0097, where $A_{\mathrm{s}}^{\prime}$ and $A_{\mathrm{s}}$ are the areas of longitudinal top and bottom reinforcement, respectively, $b_{w}$ is the section width, and $d$ is the effective section depth. Rogowsky et al. ${ }^{1}$ and Ashour ${ }^{3}$ showed that the difference between the amount of longitudinal top and bottom reinforcement had little influence on the structural behaviour of continuous deep beams failed in shear owing to crushing of diagonal concrete struts joining the load and support points. The longitudinal bottom reinforcement was continuous over the full length of the beam and welded to $160 \times 100 \times 10 \mathrm{~mm}$ end plates. The longitudinal top reinforcement was anchored outside the end support by a $90^{\circ}$ hook according to ACI $318-05 .{ }^{10}$ The clear cover to longitudinal top and bottom reinforcement was $35 \mathrm{~mm}$. Two horizontal deformed steel bars of $10 \mathrm{~mm}$ diameter were placed immediately above openings to ease the arrangement of inclined web reinforcement and transfer tensile forces by strut-and-tie action as suggested by Tan et $a l .^{8}$

\subsection{Material properties}

The design compressive strength of concrete was $55 \mathrm{MPa}$. The ingredients of ready-mixed concrete used to cast test specimens were ordinary Portland cement, fly-ash, irregular gravel of a maximum size of $25 \mathrm{~mm}$ and sand with a maximum size of $5 \mathrm{~mm}$. The water-binder ratio by mass was 31\% and 25\% of fly-ash to the mass of cement was added. Three control cylinders were cast and cured simultaneously with each beam to determine the concrete compressive strength, which was the same in all beams at 50.52 MPa.

Both $19 \mathrm{~mm}$ and $10 \mathrm{~mm}$ diameter steel bars were tested in tension according to the Korean Industrial Standard. ${ }^{15}$ Table 2 shows the mechanical properties of all reinforcement used in the beams tested. 


\subsection{Instrumentation and test set-up}

Figure 2 shows the loading and instrumentation arrangement of beams tested. All beams having two spans were tested to failure under a symmetrical two-point top loading system with a loading rate of $30 \mathrm{kN} / \mathrm{min}$ using a $3000 \mathrm{kN}$ load capacity universal testing machine (UTM). Each span was identified as W-span or E-span as shown in Figs 1 and 2. The two exterior end supports are designed to allow horizontal and rotational movements whereas the intermediate support prevents horizontal movement but allows rotation. In order to evaluate the shear force and loading distribution, $1000 \mathrm{kN}$ capacity load cells were installed at both exterior end supports.

Vertical deflections at beam mid-spans were measured using linear variable differential transformers (LVDTs). The PI-type gauges were used for monitoring diagonal crack width at concrete struts joining the edges of load or intermediate support plates and opening corners as shown in Fig. 2. The beam surface was whitewashed to aid the observation of crack development during testing. After each load increment, the load was kept constant while cracks were marked and photographed. The test data were captured by a data logger and automatically stored.

\section{EXPERIMENTAL RESULTS AND DISCUSSION}

\section{I. Crack propagation and failure mode}

Figure 3 shows the crack propagation and failure planes of tested beams having openings; the total load (in $\mathrm{kN}$ ) at which cracks occurred is also given in this figure. Just before failure, a very similar crack pattern was observed above and below openings and for both $\mathrm{W}$ and $\mathrm{E}$ spans of the beams tested. The first crack in all beam specimens occurred at opening corners near load points (at B and D in Fig. 2) and propagated towards the load points with the load increase. This first diagonal crack load at opening corners decreased with the increase of the width and depth of openings but was not influenced by the amount of inclined reinforcement, as given in Table 3. Bottom flexural cracks at the beam mid-span and top flexural cracks over the intermediate support followed and then diagonal cracks originated at opening corners opposite to the load points (at A and C in Fig. 2). Most cracks concentrated at corners of openings and diagonal cracks at exterior shear spans did not appear as shown in Fig. 3.

The amount of inclined reinforcement influenced the distribution of cracks above and below openings. Beams T1-0, T3-0, F2-0 and F3-0 without inclined reinforcement failed soon after the occurrence of diagonal cracks joining the edges of load or intermediate support plates and opening corners opposite to their plates. On the other hand, for beams tested with inclined reinforcement, several diagonal cracks developed forming a fan-shaped distribution at both top and bottom chords above and below openings. Even F-series beams having a large opening width showed good distribution of diagonal cracks when the effective inclined reinforcement factor was above 0.051, as shown in Fig. 3(g), (h), (k) and (l).

Failure planes of all tested beams having openings were formed asymmetrically along diagonal cracks joining the edges of the load and support plates and opening corners opposite to the load and reaction points, $\mathrm{AE}$ and $\mathrm{CF}$, as shown in Fig. 3. These failure planes followed the upper and lower force paths of simple deep beams with openings proposed by Kong et al., ${ }^{5}$ regardless of the effectiveness inclined reinforcement factor. The displacements of blocks formed in continuous deep beams were, however, different from those of simple deep beams. For continuous deep beams having openings within interior shear spans, the end block in failed span had rotational displacement about one end support while the other block was fixed over the intermediate and other end supports, whereas the two blocks formed in simple deep beams with web openings had rotational displacement around end supports.

\subsection{Load plotted against mid-span deflection}

Mid-span deflections at failed span for different beams tested against the total applied load are shown in Fig. 4. On the same figure, mid-span deflection of a companion solid deep beam ${ }^{14}$ is also reproduced. The initial stiffness of beams until the occurrence of the first diagonal crack at opening corners was almost independent on the opening size and amount of inclined reinforcement. After the first diagonal crack appeared, a smaller deflection was observed in beams with smaller openings and higher amount of inclined reinforcement. The stiffness after the first diagonal crack of beam T1-4 having $\xi=0 \cdot 171$ was closer to that of the companion solid deep beam. Post-failure characteristics of beams tested were also influenced by the effective inclined reinforcement factor. The beams having $\xi>0.051$ showed some ductile behaviour at failure despite the tensile splitting of concrete struts above and below openings owing to compressive force.

\subsection{Support reactions} Figure 5 shows the amount of load transferred to the end support against the total applied load. The two end 


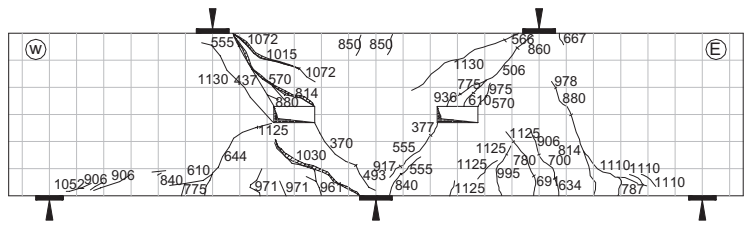

(a)

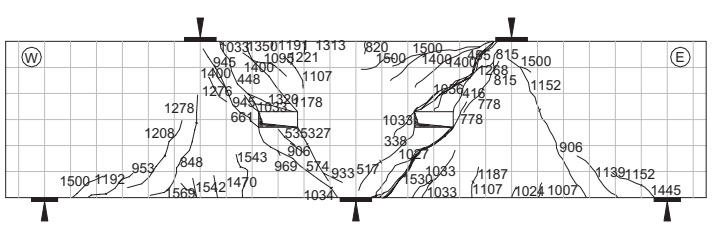

(c)

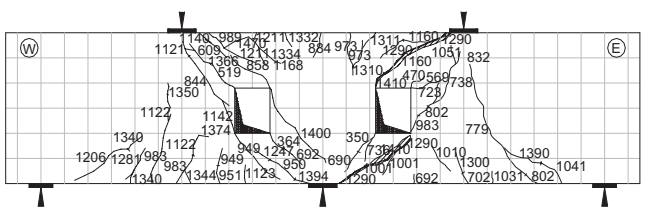

(e)

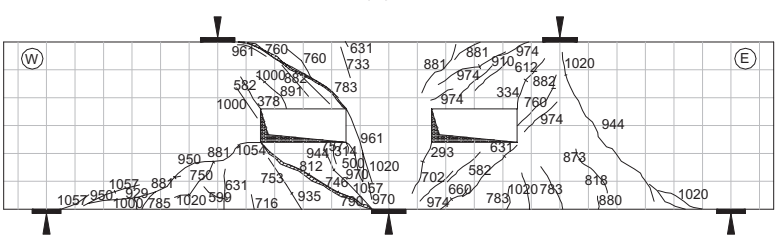

(g)

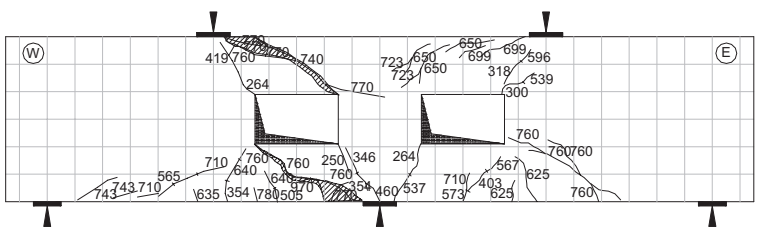

(i)

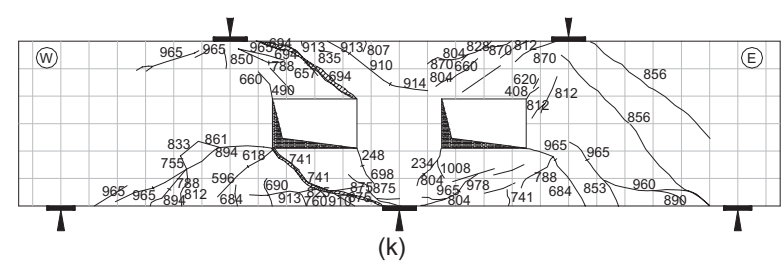

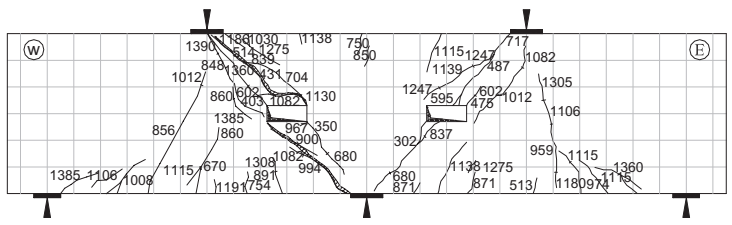

(b)

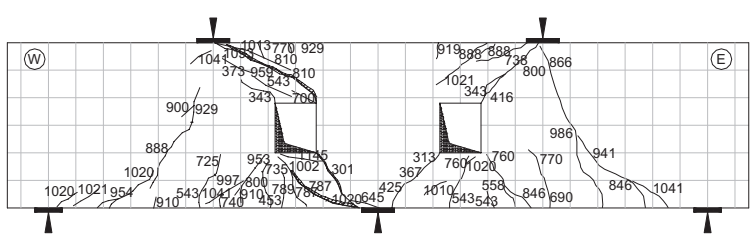

(d)

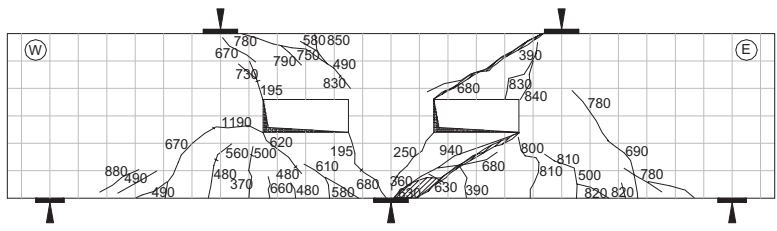

(f)

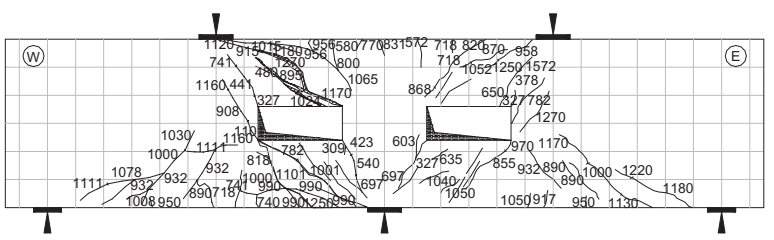

(h)

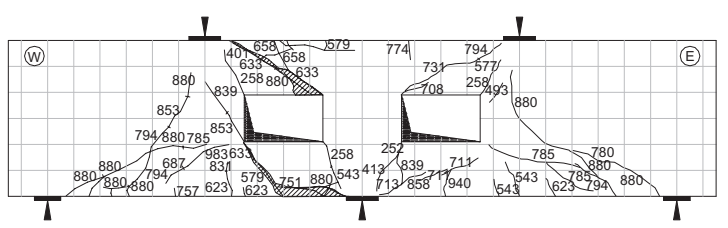

(j)

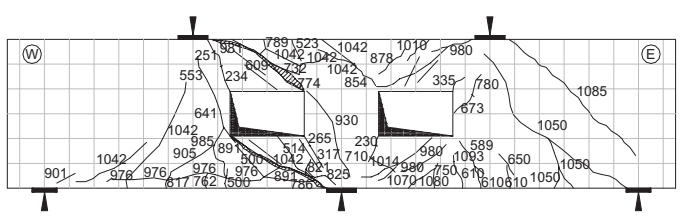

(I)

Fig. 3. Crack patterns and failure of beams tested: (a) $\mathrm{TI}-0(\xi=0)$; (b) $\mathrm{TI}-2(\xi=0.086)$; (c) $\mathrm{TI}-4(\xi=0.17 \mathrm{I})$; (d) $\mathrm{T} 3-0$ ( $\xi=0)$;

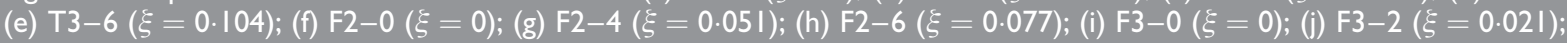
(k) F3-4 ( $\xi=0.04 \mathrm{I})$; (I) F3-6 $(\xi=0.062)$. (Numbers indicate the total load in $\mathrm{kN}$ at which cracks occurred)

support reactions were very similar to each other until failure as given in Table 3. The size of openings within interior shear spans and amount of inclined reinforcement had a significant influence on load distribution after the first diagonal crack in continuous deep beams. The end support reaction of a companion solid deep beam and that obtained from a linear two-dimensional finite-element (2D FE) analysis are also presented in Fig. 5. The end support reaction of beams having opening size of $0.25 a \times 0 \cdot 1 h$ was similar to that of the companion solid deep beam regardless of the amount of inclined reinforcement around openings. On the other hand, for T-series beams having opening size of $0.25 a \times 0.3 h$ and F-series beams, the larger the opening size and the smaller the amount of inclined reinforcement, the higher the end support reaction, indicating that end support reaction is becoming closer to that of the solid deep beam with the increase of the effective inclined reinforcement factor.

\subsection{Diagonal crack width}

Figure 6 shows the development of diagonal crack width against the total applied load along the diagonal plane joining the edge of the intermediate support plate and opening corner opposite to the support (DF in Fig. 2). In Fig. 6 the limit crack width of $0.4 \mathrm{~mm}$ specified for serviceability of concrete members in ACI $318-02^{16}$ is also plotted. For beams having no inclined reinforcement, as soon as the first diagonal crack occurred, the width 


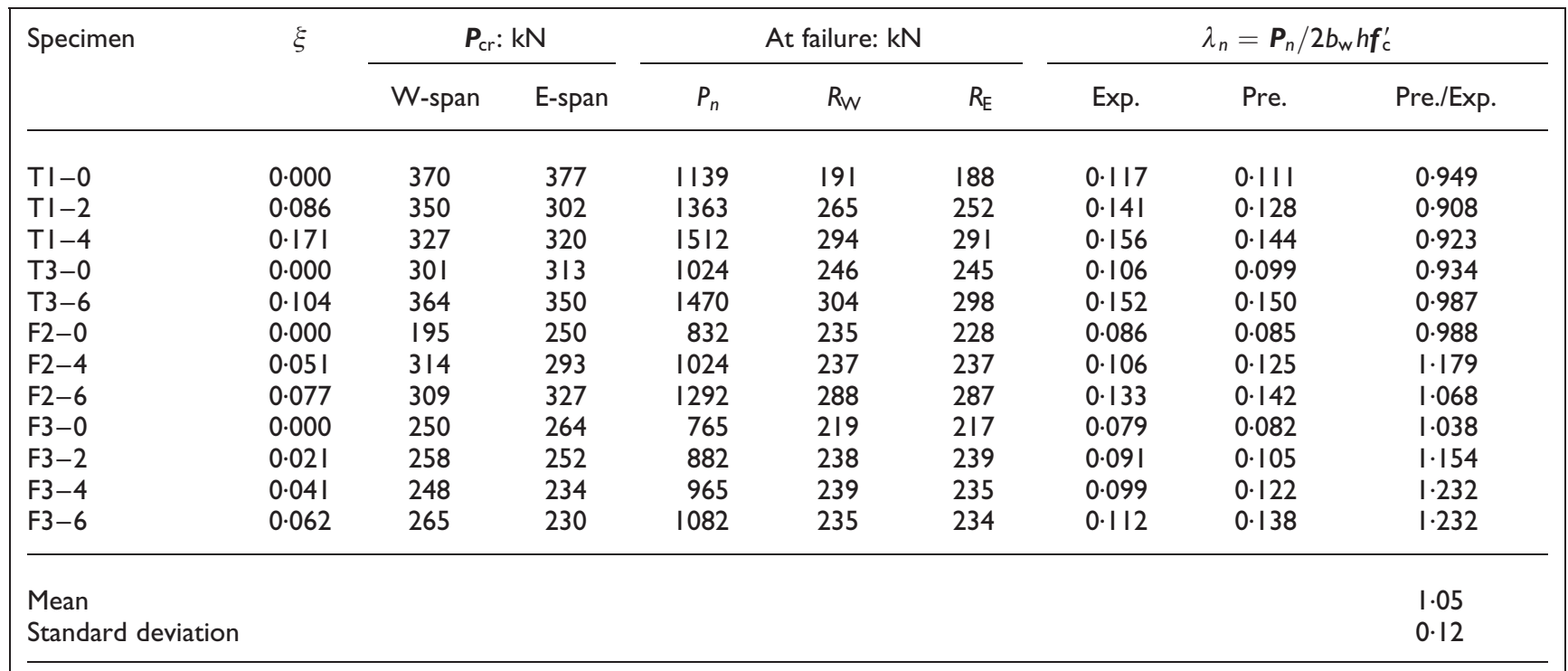

Note: $\boldsymbol{P}_{\mathrm{cr}}$ is first diagonal crack load at web opening corners; $\boldsymbol{P}_{n}$ is total failure load; $\boldsymbol{R}_{\mathrm{W}}$ is end support reaction of $\mathrm{W}$ span; and $\boldsymbol{R}_{\mathrm{E}}$ is end support reaction of $\mathrm{E}$ span.

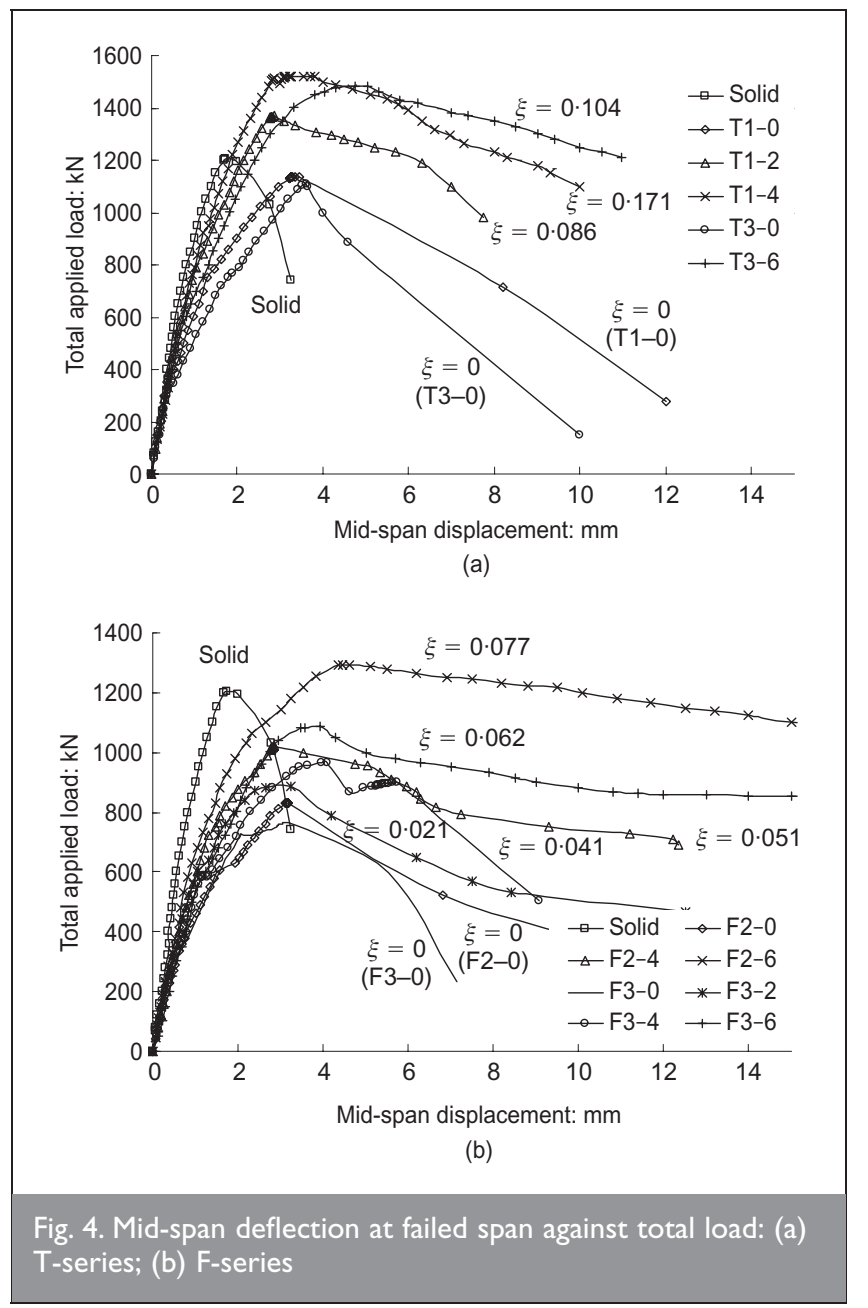

dramatically extended up to $0 \cdot 05-0 \cdot 2 \mathrm{~mm}$ and the increasing rate of the diagonal crack width against the total applied load increased with the increase of the width and depth of openings. Beam F3-2 having $\xi=0.021$ and beam F2-0 having no inclined web reinforcement but smaller opening

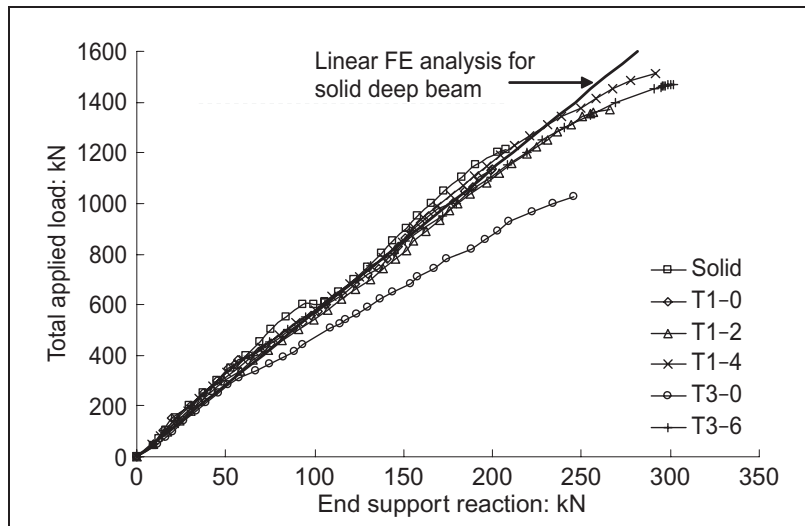

(a)

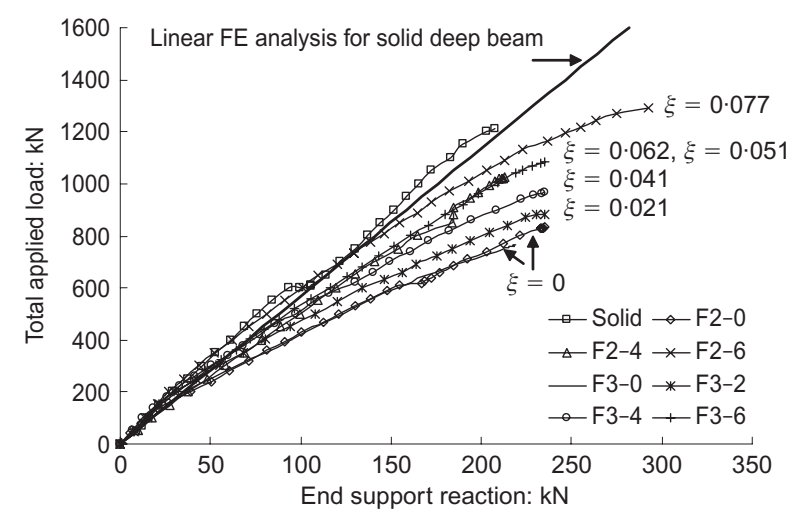

(b)

Fig. 5. End support reaction against applied load: (a) T-series; (b) F-series

than in beam F3-2 were very similar in the propagation of diagonal crack width. On the other hand, for beams having $\xi$ above $0 \cdot 041$, a sudden increase in the diagonal crack width after the first diagonal crack hardly occurred and the increasing rate of the diagonal crack width against the total 


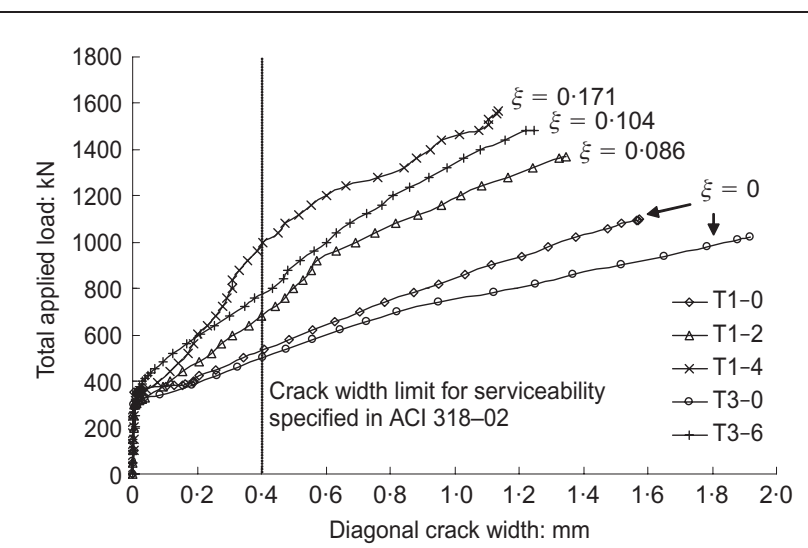

(a)

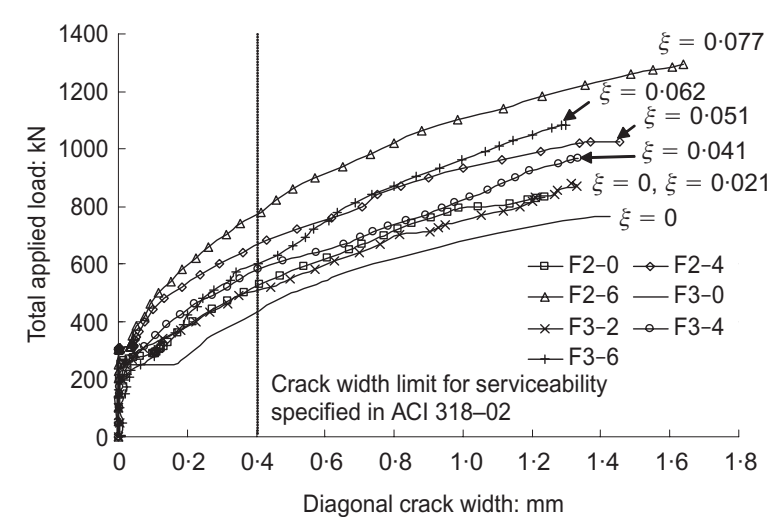

(b)

Fig. 6. Diagonal crack width below openings against total load: (a) T-series; (b) F-series

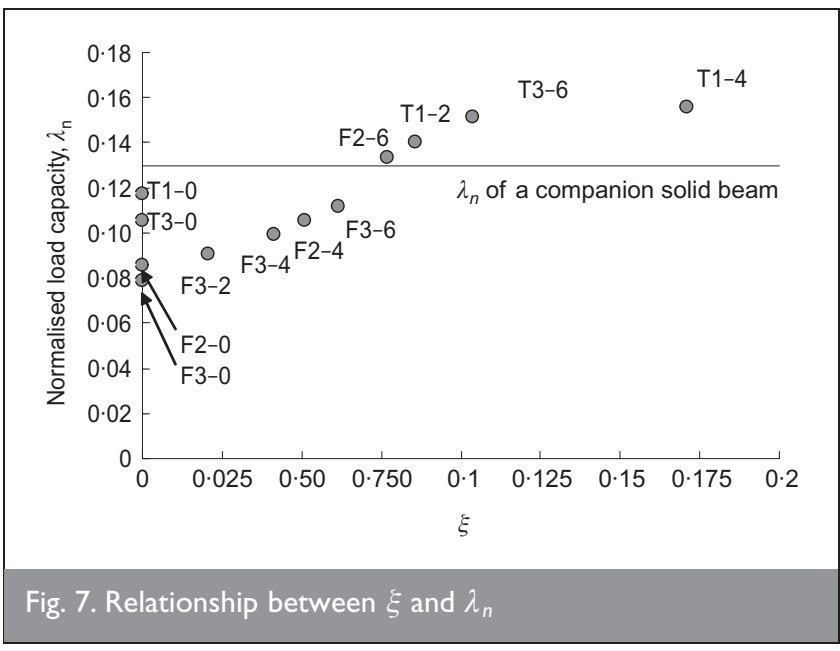

applied load decreased with the increase of the effective inclined reinforcement factor.

\subsection{Load capacity}

The influence of the effective inclined reinforcement factor $\xi$ on the normalised load capacity $\lambda_{n}=\boldsymbol{P}_{n} / 2 b_{\mathrm{w}} h \boldsymbol{f}_{\mathrm{c}}^{\prime}$, of the test specimens is shown in Fig. 7 and Table 3, where $\boldsymbol{P}_{n}$ is the total load capacity, and $\boldsymbol{f}_{c}^{\prime}$ is the concrete compressive strength. The load capacity of beams without inclined reinforcement decreased with the increase of the size of openings within interior shear spans. The load capacity of beams F2-0 and F30 whose opening width was $0.5 a$ decreased compared with that of the companion solid deep beam by $35 \%$ and $40 \%$, respectively. On the other hand, the inclined reinforcement around openings enabled beams tested to enhance their load capacity as observed in simple deep beams. ${ }^{9}$ Beams tested having $\xi>0 \cdot 077(\mathrm{~F} 2-6, \mathrm{~T} 1-2, \mathrm{~T} 3-6$ and T1-4) exhibited higher load capacity than that of the companion solid deep beam.

\subsection{Structural functions of inclined reinforcement around openings}

As shown from Figs 3-7, it can be concluded that the inclined reinforcement around openings in continuous deep beams has two main structural functions: to resist the transverse tensile force developed in concrete struts above and below openings and improve the ductility of concrete struts owing to the confinement effect. The tensile transfer capacity of inclined reinforcement enables the diagonal crack width to be effectively controlled, as pointed out by Vecchio and Collins ${ }^{17}$ and provide load transfer mechanism by truss action as proposed by Tan et al. ${ }^{8}$ As a result, inclined reinforcement around openings can compensate for the reduced beam stiffness owing to diagonal cracks around openings, which is clearly shown by Figs 4 and 5. In addition, the enhanced ductility of concrete struts helps to increase the effective concrete strength, as suggested by many researchers $2,3,7,8,17$ and code provisions. ${ }^{10,12}$

\section{MECHANISM ANALYSIS}

The failure mode of reinforced-concrete continuous deep beams having web openings within interior shear spans as presented in Fig. 3, which was observed in the current investigation and elsewhere, ${ }^{7,14}$ can be idealised as an assemblage of two rigid blocks separated by two yield lines as proposed by Ashour and Rishi. ${ }^{7}$ Rigid block I rotated about an IC and rigid block II was fixed over the intermediate and one end supports as shown in Fig. 8(a). Both upper and lower yield lines seldom have the same displacement rate and angle about IC, as they are formed discontinuously by the opening. By equating the total internal energy dissipated in concrete along the hyperbolic yield lines and in steel reinforcement crossing the yield lines to the external work done by the vertical applied load, the normalised load capacity, $\lambda_{n}=\boldsymbol{P}_{n} / 2 b_{\mathrm{w}} h \boldsymbol{f}_{\mathrm{c}}^{\prime}$, can be developed in the following form ${ }^{7,14}$

$\begin{aligned} \lambda_{n}= & \frac{1}{2 a}\left[\sum_{i=1}^{2}\left[\left(v_{\mathrm{e}}\right)_{i} r_{i}\left(1-\sin \alpha_{i}\right) l_{i}\right]\right. \\ & \left.+2 \sum_{j=1}^{n}\left(\phi_{\mathrm{s}}\right)_{j}\left(r_{\mathrm{s}}\right)_{j} \cos \left(\alpha_{\mathrm{s}}\right)_{j}\right]\end{aligned}$

where $\left(v_{\mathrm{e}}\right)_{i}$ is the effectiveness factor of concrete at yield line $i$; $\alpha_{i}$ is the angle between the relative displacement $\boldsymbol{\delta}_{i}$ at the midpoint of the chord and yield line $i$; $l_{i}$ is the length of the yield line $i ; r_{i}$ is the distance between the midpoint of the chord of the yield line $i$ and IC; $n$ is the number of reinforcing bars crossing the yield line; $\left(\phi_{\mathrm{s}}\right)_{j}=\left(A_{\mathrm{st}}\right)_{j}\left(f_{\mathrm{y}}\right)_{j} / b_{\mathrm{w}} h \boldsymbol{f}_{\mathrm{c}}^{\prime}$ is the reinforcement index for each individual reinforcing bar $j$ crossing the yield line $\left(A_{\mathrm{st}}\right)_{j} ;\left(\mathbf{f}_{\mathrm{y}}\right)_{j}$ is the area and yield strength of the reinforcing bar $j$ crossing the yield line, 


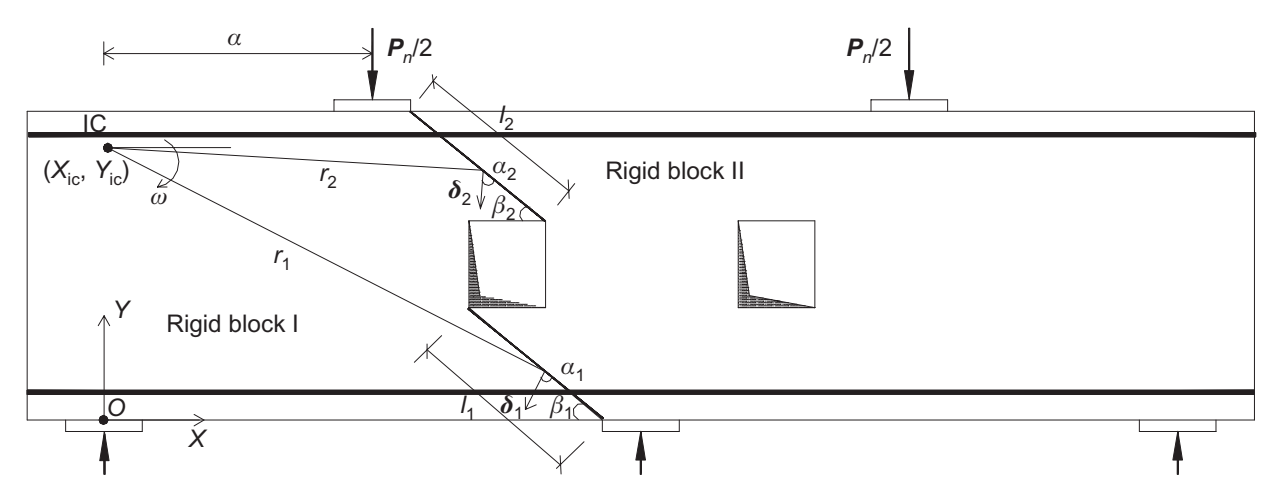

(a)

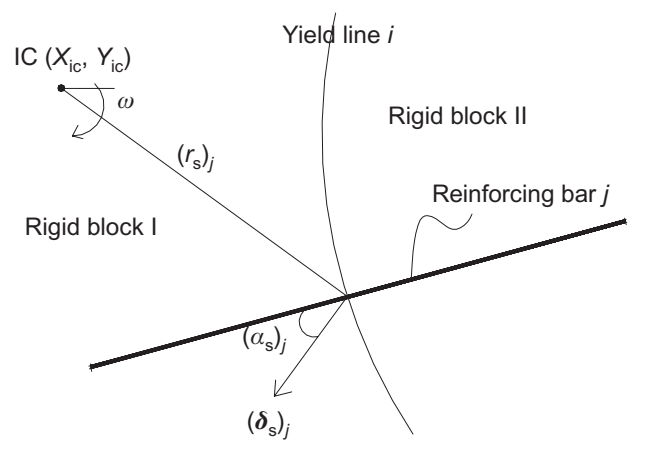

(b)

Fig. 8. Idealised failure mode of deep beam having openings within interior shear spans: (a) concrete blocks separated by yield line; (b) reinforcing bar crossing yield line

respectively; $\left(r_{\mathrm{s}}\right)_{j}$ is the distance between the intersection point of reinforcing bar $j$ with yield line and IC; $\left(\alpha_{s}\right)_{j}$ is the angle between the relative displacement $\left(\boldsymbol{\delta}_{\mathrm{s}}\right)_{j}$ of the reinforcing bar $j$ about IC and the reinforcing bar $j$ crossing the yield line as shown in Fig. 8(b).

In equation (2), longitudinal and inclined reinforcing bars are assumed to be a rigid perfectly plastic material with yield strength $f_{\mathrm{y}}$, and their dowel action is neglected.

\section{I. Effectiveness factor of concrete}

In developing the above equation, concrete is regarded as a rigid perfectly plastic material with an effective compressive strength $f_{\mathrm{c}}^{*}\left(=v_{\mathrm{e}} \boldsymbol{f}_{\mathrm{c}}^{\prime}\right)$ and obeying the modified Coulomb failure criteria with zero tension cut-off. ${ }^{18}$ The effectiveness factor of concrete proposed by Vecchio and Collins ${ }^{17}$ is adopted in the present study and also modified to consider the influence of size effect as follows

$\begin{aligned}\left(v_{\mathrm{e}}\right)_{i} & =\frac{\varsigma_{i}}{1 \cdot 0+\left(K_{\mathrm{c}}\right)_{i} K_{f}} \\ \left(K_{\mathrm{c}}\right)_{i} & =0.35\left(-\frac{\left(\boldsymbol{\varepsilon}_{1}\right)_{i}}{\left(\boldsymbol{\varepsilon}_{3}\right)_{i}}-0.28\right)^{0.8} \geqslant 1 \cdot 0 \\ K_{f} & =0.1825 \sqrt{f_{\mathrm{c}}^{\prime}} \geqslant 1 \cdot 0 \\ \varsigma_{i} & =\frac{1}{\sqrt{1+\frac{\left(d_{\mathrm{s}}\right)_{i}}{25 d_{\mathrm{a}}}}}\end{aligned}$

where $\left(\boldsymbol{\varepsilon}_{1}\right)_{i}$ and $\left(\boldsymbol{\varepsilon}_{3}\right)_{i}$ are the principal tensile and compressive strains in the yield line $i$, respectively. As the principal strains $\left(\boldsymbol{\varepsilon}_{1,3}\right)_{i}$ are $1 / 2\left(\delta_{i} / \Delta_{i}\right)\left(\sin \alpha_{i} \pm 1\right)$ in the yield line $i$ having discontinuous width of $\Delta_{i}$ from the plasticity theory, ${ }^{18}$ $\left(-\varepsilon_{1} / \varepsilon_{3}\right)_{i}$ in factor $\left(K_{\mathrm{c}}\right)_{i}$ can be written as $1+\sin \alpha_{i} / 1-\sin \alpha_{i}$. This indicates that the influence of the transverse tensile strain on the effectiveness factor can be determined by the angle $\alpha_{i}$. The factor $\varsigma_{i}$ proposed by Bažant and Kim, ${ }^{19}$ which is a function of the depth $\left(d_{\mathrm{s}}\right)_{i}$ of yield line $i$ and the maximum size $d_{\mathrm{a}}$ of aggregate, is to reflect the influence of the size effect which is significant in deep beams.

\subsection{Solution procedure}

The load capacity of continuous deep beams having openings within interior shear spans is implicitly expressed as a function of the position of the instantaneous centre $\left(X_{\text {ic }}, Y_{\text {ic }}\right)$ as given in equation (2). As the vertical displacement at the end support beneath rigid block I is prevented, the IC can be located along the end support. The process of tuning the vertical coordinate $\left(Y_{\text {ic }}\right)$ to obtain the minimum value of the load capacity is achieved by reliable numerical optimisation procedures provided in MATLAB software.

\subsection{Comparisons of predicted and experimental failure loads}

To examine the validity of the proposed model, comparisons between the predictions and experimental results of the normalised load capacity are given in Table 3 and Fig. 9. The failure load of beams having large opening size of $0.5 a \times 0.3 h$ is slightly overestimated using equation (2). The mean and 


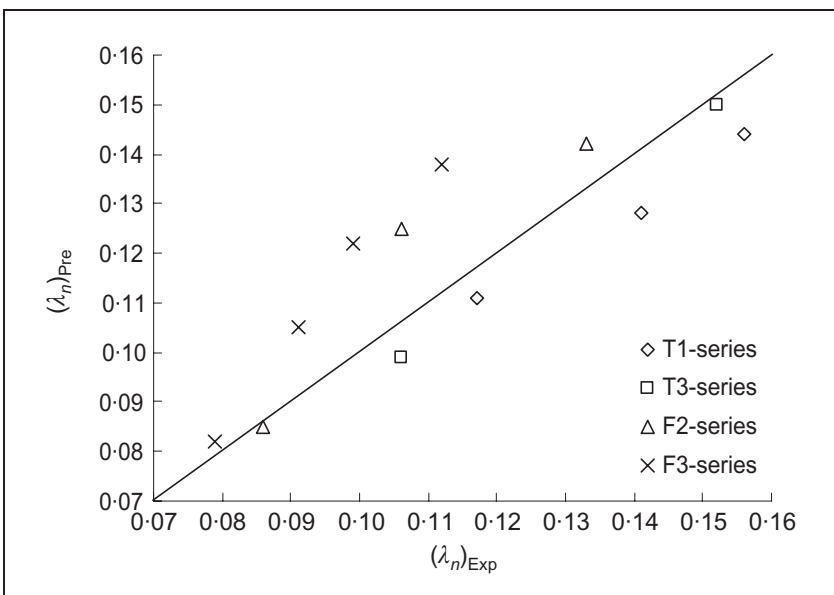

Fig. 9. Comparison of predicted and measured load capacities

standard deviation of the ratio between the predicted and experimental failure loads are 1.05 and $0 \cdot 12$, respectively. Overall, the proposed mechanism analysis reasonably predicted the failure loads of the tested continuous deep beams having web openings within interior shear spans.

\section{CONCLUSIONS}

Twelve reinforced-concrete continuous deep beams having web openings within interior shear spans were tested to failure. The main variables investigated were the opening size and amount of inclined reinforcement around openings. Test results are analysed against an effective inclined reinforcement factor. In addition, the load capacity of beams tested is compared with prediction obtained from a numerical technique based on the upper-bound analysis of the plasticity theory. The following conclusions can be drawn.

(a) Several diagonal cracks developed, forming a fan-shaped distribution at both top and bottom chords above and below openings of beams having web-inclined reinforcement-unlike the beams with no inclined web reinforcement. Even beams having opening width of half the shear span showed good distribution of diagonal cracks when the effective inclined reinforcement factor was $>0.051$.

(b) The end support reaction of beams having an opening area ratio of 0.025 was similar to that of the companion solid deep beam regardless of the amount of inclined reinforcement. On the other hand, for beams having an opening area ratio $>0.075$, the end support reactions became closer to those of the companion solid deep beam with the increase of the effective inclined reinforcement factor.

(c) A sudden increase of diagonal crack width after the occurrence of the first diagonal crack hardly occurred in beams having an effective inclined reinforcement factor $>0.041$, and the increasing rate of the diagonal crack width against the total applied load decreased with the increase of the effective inclined reinforcement factor.

(d) The load capacity of deep beams having openings within interior shear spans increased with the increase of the effective inclined reinforcement factor. Beams having an effective inclined reinforcement factor $>0.077$ exhibited a higher load capacity than that of the companion solid deep beam.

(e) The mechanism analysis proposed to predict the load capacity of continuous deep beams having web openings within interior shear spans showed good agreement with experimental results.

\section{ACKNOWLEDGEMENTS}

This work was supported by the Korea Research Foundation Grant (KRF-2004-041-D00746) and the Regional Research Centers Program (Bio-housing Research Institute), granted by the Korean Ministry of Education and Human Resources Development. The authors wish to express their gratitude for financial support.

\section{REFERENCES}

1. Rogowsky D. M., MAcGregor J. G. and ONG S. Y. Tests of reinforced concrete deep beams. ACI Journal, 1986, 83, No. 4, 614-623.

2. YANG K. H., Chung H. S. and Ashour A. F. Influence of shear reinforcement on reinforced concrete continuous deep beams. ACI Structural Journal (accepted for publication).

3. Ashour A. F. Tests of reinforced concrete continuous deep beams. ACI Structural Journal, 1997, 94, No. 1, 3-12.

4. Kong F. K. and Planas J. Structural idealization for deep beams with web openings. Magazine of Concrete Research, 1977, 29, No. 99, 81-91.

5. Kong F. K., Sharp G. R., Appleton S. C., BeAumont C. J. and KUBIK L. A. Structural idealization for deep beams with web openings: further evidence. Magazine of Concrete Research, 1978, 30, No. 103, 89-95.

6. YANG K. H., EUN H. C. and ChUnG H. S. The influence of web openings on the structural behavior of reinforced high-strength concrete deep beams. Engineering Structures, 2006, 28, No. 13, 1825-1834.

7. Ashour A. F. and RISHI G. Tests of reinforced concrete continuous deep beams with web openings. ACI Structural Journal, 2000, 97, No. 3, 418-426.

8. TAN K. H., Tong K. and TANG C. Y. Consistent strut-and-tie modelling of deep beams with web openings. Magazine of Concrete Research, 2003, 55, No. 1, 65-75.

9. YAng K. H., Chung H. S. and Ashour A. F. Influence of inclined web reinforcement on reinforced concrete deep beams with openings. ACI Structural Journal (accepted for publication).

10. American Concrete Institute. ACI Committee 318 : Building Code Requirements for Structural Concrete (ACI 318-05) and Commentary (ACI 318R-05). ACI, Detroit, 2005.

11. Canadian Standards Association. Canadian CSA Building Code, Design of Concrete Structures: Structures (Design)-A National Standard of Canada (CAN-A23.3-94), Clause 11.1.2. Canadian Standards Association, Toronto, 1994.

12. COMItÉ EURO-INTERNATIONAL DU BÉTON-FÉDÉRATION InTERNATIONAL DE LA PRÉCONTRAINTE. CEB-FIP MC 90, Design of Concrete Structures. CEB-FIP Model Code 1990. Thomas Telford, London, 1993.

13. CONSTRUCTION INDUSTRY RESEARCH AND INFORMATION Association. The Design of Deep Beams in Reinforced 
Concrete (CIRIA 2). Ove Arup \& Partners and CIRIA, London, 1997.

14. YANG K. H. and Ashour A. F. Structural behavior of reinforced concrete continuous deep beams with web openings. Magazine of Concrete Research 2007, forthcoming.

15. KOREAN StANDARDS InfoRMATION CENTER. Korean Industrial Standard. Korean Standards Information Center, South Korea, 2006.

16. AMERICAN CONCRETE InSTITUTE. ACI Committee 318: Building
Code Requirements for Structural Concrete (ACI 318-02) and Commentary (ACI 318R-02). ACI, Detroit, 2002.

17. VeCCHIO F. J. and Collins M. P. Compression response of cracked reinforced concrete. Journal of Structural Engineering ASCE, 1993, 119, No. 12, 3590-3610.

18. Nielsen M. P. Limit Analysis and Concrete Plasticity. Prentice-Hall, Englewood Cliffs, New Jersey, 1984.

19. BAŽANT Z. P. and KiM J. K. Size effect in shear failure of longitudinally reinforced beams. ACI Journal, 1984, 81, No. 5, 456-468.

\section{What do you think?}

To comment on this paper, please email up to 500 words to the editor at journals@ice.org.uk

Proceedings journals rely entirely on contributions sent in by civil engineers and related professionals, academics and students. Papers should be 2000-5000 words long, with adequate illustrations and references. Please visit www.thomastelford.com/journals for author guidelines and further details. 